\title{
Parasitic infection as a potential therapeutic tool against rheumatoid arthritis (Review)
}

\author{
SHADIKE APAER ${ }^{1,2^{*}}$, TUERHONGJIANG TUXUN ${ }^{1,2^{*}}$, HAI-ZHANG MA $^{1}$, HENG ZHANG $^{1}$, \\ AMINA AIERKEN ${ }^{3}$, ABUDUSALAMU AINI $^{1}$, YU-PENG LI ${ }^{1}$, REN-YONG LIN ${ }^{1}$ and HAO WEN ${ }^{1,2}$ \\ ${ }^{1}$ State Key Laboratory of Xinjiang Major Diseases Research and Xinjiang Key Laboratory of Echinococcosis; \\ ${ }^{2}$ Department of Liver and Laparoscopic Surgery, Digestive and Vascular Centre; ${ }^{3}$ Department of Ultrasonography, \\ First Affiliated Hospital of Xinjiang Medical University, Urumqi, Xinjiang 830054, P.R. China
}

Received 16 June, 2015; Accepted July 15, 2016

DOI: $10.3892 /$ etm.2016.3660

\begin{abstract}
Parasites, which are a recently discovered yet ancient dweller in human hosts, remain a great public health burden in underdeveloped countries, despite preventative efforts. Rheumatoid arthritis is a predominantly cosmopolitan health problem with drastic morbidity rates, although encouraging progress has been achieved regarding treatment. However, although various types of methods and agents have been applied clinically, their broad usage has been limited by their adverse effects and/or high costs. Sustained efforts have been exerted on the 'hygiene hypothesis' since the 1870s. The immunosuppressive nature of parasitic infections may offer potential insight into therapeutic strategies for rheumatoid arthritis, in which the immune system is overactivated. An increasing number of published papers are focusing on the preventive and/or curative effect of various parasitic infection on rheumatoid arthritis from experimental studies to large-scale epidemiological studies and clinical trials. Therefore, the present review aimed to provide a general literature review on the possible beneficial role of parasitic infection on rheumatoid arthritis.
\end{abstract}

\section{Contents}

1. Introduction

2. Hygiene hypothesis

3. Parasites as immune modulators

4. Therapeutic effects of parasitic infection

5. Conclusion

Correspondence to: Professor Hao Wen, State Key Laboratory of Xinjiang Major Diseases Research and Xinjiang Key Laboratory of Echinococcosis, First Affiliated Hospital of Xinjiang Medical University, 137 Liyushan South Road, Urumqi, Xinjiang 830054, P.R. China

E-mail: dr.wenhao@163.com

*Contributed equally

Key words: rheumatoid arthritis, parasite, immune response

\section{Introduction}

Autoimmunity describes immune activation of the immune system that produces sustained damage to its own tissues and cells without any known external influences (1). Both adaptive and innate immune systems are involved in its progression. Autoimmune disease (AD), which refers to the progression of autoimmunity as a pathogenic condition, is characterized by chronic inflammation and immune dysregulation that may lead to vascular pathology, arterial lesions, enhanced autoantibody production (2) and mortality if left uncontrolled. AD manifests in numerous forms and, to date, has been predominantly detected in industrialized and developed countries and regions. A previous epidemiological observational study by Cooper et al (3) reported the estimated prevalence of AD to be $7.6-9.4 \%$, including 29 ADs. A more recent study by Hayter and Cook (4) claimed a cumulative overall prevalence of $4.5 \%$ among 81 ADs. Although a sustained effort has been made in the field to study AD at both a basic experimental and clinical level, with promising achievements, the underling mechanism is yet to be fully elucidated. It is well-known that the majority of the ADs are caused by a breakdown of immune tolerance via mechanisms that remain unclear. For systematic $\mathrm{AD}$, it has been hypothesized that the mechanism may be associated with the impaired balance between pathogen recognition and the avoidance of self-attack (5).

As one of the most common ADs, rheumatoid arthritis (RA) is characterized by systemic chronic inflammatory disorders that mainly affect symmetric diarthrodial joints and consequently destroy the tissues. RA predominantly involves the synovial tissue and mediates severe inflammation, thus leading to functional disability and, potentially, mortality. The estimated incidence of RA is $0.5-2.0 \%$ with an obvious female predominance (6). Although RA can affect individuals at any age, the highest incidence has been demonstrated to be in the fourth and fifth decades with an increasing trend associated with aging (7). Notably, RA has a substantial socio-economic effect due to lost productivity (8). The underling mechanism of RA is yet to be fully elucidated; however, it is associated with various metabolic component changes, including total cholesterol, low-density lipoprotein cholesterol and insulin sensitivity, which may even occur during a preclinical stage 
of RA (9-12). Moreover, the systemic inflammation caused by $\mathrm{RA}$ is an important independent risk factor for cardiovascular disease, and the cardiovascular risk components also increase the inflammatory burden of RA $(13,14)$. The clinical features of RA include pain, joint swelling, stiffness, weakness at local lesions, deformity, erythema and weight loss. Various therapeutic methods, from conventional disease-modifying anti-rheumatic drugs to biologics to ease the symptoms, have been employed to reduce the progression of RA and improve the disease outcomes (15). It is the proposition of the 'Hygiene hypotheses' that aroused the broad interest of researchers and propelled them to link ADs and parasitic infection. Some researchers argue that parasites may be used as an effective treatment option for RA (16-19).

\section{Hygiene hypothesis}

Parasitic infection continues to be a major public health issue and threaten the lives of humans and their domestic livestock in poorly resourced areas. Parasites have evolved to evade the host immune system (20). In line with this, there has been an increasing trend of patients with ADs exhibiting an ever-decreasing incidence of parasitic infections in developed countries and regions (3). Furthermore, previous epidemiological studies have indicated the reduced incidence of ADs in poorly endemic regions $(21,22)$. Therefore, the concept of an inverse relationship between the global distribution of ADs and the parasitic infections has been widely presented and is known the 'Hygiene hypothesis'. This hypothesis, which was named as 'Old Friends' hypotheses contemporarily, can be traced back to the 1870s when Charles Harrison Blackley noted that the incidence of hayfever was increased in aristocrats and city dwellers, as compared with farmers (23). Although it has taken various forms, the term 'Hygiene hypothesis' was coined by epidemiologist Strachan (24) in 1989, depicting the striking decrease in the prevalence of allergic diseases and an association with the increased number of family members who infected or had contact with unhygienic older siblings. Greenwood et al (21) were the first to report an inverse relationship between parasitic infection and AD. Another study suggested that the depletion of organisms from the urban environment in wealthy areas as one of the main reasons for the increased prevalence of chronic inflammatory disorders (25). Subsequently, various epidemiological and experimental studies confirmed the protective role of parasites and their excretory/secretaries upon various ADs, including type 1 diabetes mellitus, multiple sclerosis, RA and autoimmune thyroid disease $(22,26,27)$. Furthermore, studies have shown that modulation of the host immune response by parasitic helminthes may have a concomitant health benefit as it may protect helminthes from being eradicated, and simultaneously protect the host from excessive pro-inflammatory responses $(28,29)$.

The potential protective role of parasitic infections on RA has provided insight into the novel therapeutic modalities, which may interfere with the initiation of RA and alleviate its severity. Despite minimal evidence against the beneficial role of parasites (30-32), the potential beneficial role of parasites has been widely elucidated in numerous studies through human and animal experimentation $(16,17,19,33)$.
Therefore, the present review focused on the reciprocal relationship between parasitic infection and RA and its possible mechanisms involving cell immunity modulation and relative cytokine level alterations.

\section{Parasites as immune modulators}

Among infectious agents, parasites are regarded as important manipulators and regulators of immune system (34). Parasites have evolved to secrete a range of immune-modulatory molecules, which are referred to as parasite-derived products that have the ability to target various host cells and exert the capacity to directly modulate host immune functions (35). Moreover, various parasitic extracts have been characterized, both in terms of structure and bioactivity $(36,37)$. Maintaining a disease-tolerant or asymptomatic condition during parasitic infection requires adequate and successful crosstalk between the host immune system and the parasites. Therefore, parasites are likely to gradually modify, downregulate and divert the host immune response pattern for their own continuous survival. In brief, co-evolution and mutual adaptation have occurred between parasites and the human immune system.

It is well accepted that parasitic infections are typically characterized by inducing and/or skewing the host immune response towards a strong type 2 immune response, which is defined by the presence and activation of Th2 cells with the ability to secrete interleukin (IL)-4, IL-5 and IL-13 $(28,38)$. $\mathrm{CD}^{+} \mathrm{T}$ cells are central in this pattern, as described in studies where $\mathrm{CD}^{+} \mathrm{T}$-deficient mice were unable to clear parasites or express anti-helminthic immune responses $(39,40)$. In line with this, depletion of Th2-related key signaling molecules, such as IL-4 receptor alpha chain (IL-4R $\alpha$ ) and signal transducer and activator of transcription 6 (STAT6) in different parasitic infections resulted in a failure to expel the parasite and increased susceptibility to parasitic infections $(41,42)$. In another study, a lack of GATA3 transcription factor led to diminished Th2 cell differentiation (43).

With the discovery and definition of novel $\mathrm{T}$ helper cells, researchers have indicated the significant role of $\mathrm{T}$ helper 17 cells, T regulatory (Treg) cells, Th9 and Th22 cells in parasitic infection immunity. As indicated in a previous experimental study, elevated Th17/IL-17 levels in a model of Schistosoma japonicum infection were associated with severe immunopathology, and treatment with IL-17 antibody neutralization significantly ameliorated hepatic granulomatous inflammation (44). Besides, it has been indicated that the severe immune-pathogenic role of IL-17 is dependent on IL-23 in S. japonicum infection (45). Furthermore, studies have elucidated the presence and functional significant role of $\mathrm{CD}^{+}{ }^{+} \mathrm{Foxp}^{+}$natural regulatory $\mathrm{T}$ cells during schistosome egg-infected immune responses and human filarial parasite infection, which suggests that these cells may be able to prevent detrimental Th1 cytokine production and induce a Th2 polarized immune response in a IL-10 independent manner to suppress the host's immunity to parasites $(46,47)$. As another study indicated, the effector $\mathrm{T}$ helper cell responses induced by parasite eggs are controlled by Treg cells (48). Moreover, IL-9, which is a functional cytokine of Th9 cells, were demonstrated to have a protective role for the host and have been associated with accelerated expulsion of the parasite 
from the intestine and resistance to the intestinal nematode Trichuris muris activity (49).

\section{Therapeutic effect of parasite infection}

Previous human and animal studies have claimed that certain parasitic infections can reduce the immune system response to some ADs. Suppression and reduction, in terms of incidence as well as severity scores of adjuvant arthritis, has been reported as early as in rats infected with Plasmodium berghei in 1970 (16). Furthermore, in 1975, the protective role of the nematode Syphacia oblevata was reported in experimental rat models of RA (17). Similar protective effects have been successively demonstrated in experimental infection with S. japonicum, S. mansoni, Ascaris suum and Hymenolepsis diminuta $(18,19,33)$.

Although the etiology of RA has not been fully elucidated, there is evidence to support the significant role of $\mathrm{CD}^{+} \mathrm{T}$ cells in the initiation and perpetuation of chronic autoimmune inflammation responses $(50,51)$. In patients with $\mathrm{RA}, \mathrm{CD} 4^{+}$ $\mathrm{T}$ cells, which are the main orchestrator of cell mediated immune responses, were enriched in synovial tissue. Furthermore, antigen-activated $\mathrm{CD} 4^{+} \mathrm{T}$ cells promoted the secretion of cytokines and chemokines, including IL-6, IL-1, interferon- $\gamma$ (IFN- $\gamma$ ), and lymphotoxin and tumor necrosis factor (TNF)- $\beta$, which aggravate joint inflammation (52). A similar detrimental effect of severe joint inflammation, bone and cartilage destruction of activated $\mathrm{T}$ cells was also observed in a rat model of adjuvant-induced arthritis (53). Upon activation with specific antigens, $\mathrm{CD}^{+} \mathrm{T}$ cells differentiate into varying subsets, such as Th1, Th2 and Treg cells, which are marked with distinct cytokine secretion patterns and effective functions. It is generally accepted that RA is mediated by Th1 cell responses that are predominantly associated with pro-inflammatory interactions that exacerbate the inflammation and joint destruction and promote humoral immunity (19). It has been suggested that the initiating phase is strictly $\mathrm{T}$ cell dependent and under the control of $\mathrm{T}$ cell derived cytokines (54). The chronic phase is mediated by humoral immunity (51). Collagen-induced arthritis (CIA) model, in which immune tolerance is broken by immunization with bovine/chicken collagen and complete Freund's adjuvant (CFA), is believed to be the most commonly used animal model for resembling human RA in terms of clinical, histological, and immunological features as well as genetic linkage (55). Moreover, the development of arthritis is also accompanied by cellular and humoral immune responses to collagen, making it more suitable for better understanding of both innate and adaptive immune responses during RA progression (56).

Cytokines have a central role in the regulation of the immune system and are involved in inflammatory processes as well as in the pathogenesis of numerous diseases (57). An abundant amount of cytokines, including IL-1, IFN- $\gamma$, TNF- $\alpha$ and IL-12, which regulate or mediate Th1 responses have been detected in RA synovial tissues. TNF- $\alpha$ and IL-1 have primary roles in the pathogenesis of RA with high expression in the serum and synovial fluid of patients with active RA. TNF- $\alpha$ and IL-1 are able to activate chondrocytes and synovial fibroblasts which release tissue, thereby destroying matrix metalloproteinases, which are the main mediators of joint damage in RA (58). Meanwhile, Th1 cell differentiation is promoted by IL-12 and IFN- $\gamma(5)$ IFN- $\gamma$ receptor knockout mice are more sensitive to the induction of CIA $(59,60)$, and exhibit severe clinical and histological arthritis more readily with significantly elevated $\operatorname{IgG} 1$ and $\operatorname{IgG} 2 \mathrm{~b}$ antibodies to the auto-antigen murine type-2 collagen (CII) levels compared with normal wild-type mice $(61,62)$. T cell-specific transcription factor (T-bet), which is the important transcription factor and master regulatory factor for Th1 cells, signal transducer and activator of transcription 4 (STAT4), is associated with an increased risk for RA (63), and its promoting cytokine IL-12 and inducer IFN- $\gamma$ are indispensable for the induction and development of RA (64).

$\mathrm{Th} 2$ immune responses are evoked in response to parasitic infections characterized by enhanced secretion of IL-4, IL-5 and other Th2-related cytokines and are hypothesized to have the ability to suppress pro-inflammatory Th1 immune response (65). Besides, Th2 cells were associated with the down-regulation of macrophage activation and can release or recruit strong inflammatory components. As anti-inflammatory effectors, Th2 cells antagonize the function and development of Th1 cells; for instance, IL-4, which is the signature cytokine predominantly secreted by Th2 cells, is able to block the differentiation of Th1 cells and downregulate pre-inflammatory cytokines such as TNF- $\alpha$ and IL-1 $\beta$. Another leading hypothesis states that parasitic infestations protect against Th1-associated ADs such as RA by inducing immune regulatory networks driven by Treg cells and IL-10 (66). Treg cells have been shown to have a protective role against tissue injury and can limit inflammation responses (67). It has been indicated that Treg cells in parasite-infected individuals are the main resource of IL-10 (68), which is important for immune regulation and host survival (69). Besides, DBA mice infected with $S$. mansoni prior to immunization with CII exhibited reduced levels of Th1 (IFN- $\gamma$ ) and pro-inflammatory cytokine (TNF- $\alpha$ and IL-17A) levels and elevated Th2 (IL-4) and anti-inflammatory cytokine (IL-10) levels in their paws and ConA-stimulated spleens cells (19). Abrogated pro-inflammatory cytokines (IL-1 $\beta$ and IL-6) and receptor activator of NFkB were also detected in inflamed paws (19). Type 2 immune responses induced by parasitic infection can control and suppress Th1-mediated inflammatory pathogens like RA that involve a wide range of cytokine alterations. Parasitic infection has been shown to ameliorate the severity of RA in a number of animal models by reducing CII-specific antibodies and inflammatory cytokine production $(18,33)$. In addition, pathological severity was negatively correlated with parasite burden. In line with this, there are several lines of evidence focusing on the beneficial effect of different parasites on RA. Pearson and Taylor $(17,23)$ reported that rats infected with $S$. oblevata suffered from a reduced incidence rate and less severe form of Freund's complete adjuvant arthritis than non-infected rats. To test the effect of $S$. mansoni infection on RA, Osada et al (19) infected DBA mice two weeks prior to CII immunization, and all data including joint tissues, clinical observational materials were analyzed. Reduced severity of CIA, decreased histopathological changes in paw tissues and lowered specific anti-CII IgG (IgG1 and IgG2a) levels were detected in the infected mice. Downregulation of Th1 (IFN- $\gamma$ ) and pro-inflammatory cytokines (TNF- $\alpha$ and IL-17A) were 
also detected in spleen cell culture supernatants (19). Similar changes in cells and cytokines were observed in animals infected with S. japonicum, and IFN- $\gamma$, T-bet and ROR $\gamma$ t were downregulated (19). Such an alteration in the immune response pattern was believed to contribute to the reduced severity of autoimmune arthritis and supported the hypothesis that $S$. japonicum infection is able attenuate the severity of autoimmune arthritis via systemic and local suppression of pro-inflammatory mediators, and further suggested that parasite-derived materials may be used as therapeutic agents against RA. Similar protective effects have been observed in experimental infection with A. suum. DBA/1J mice subjected to CIA were infected with A. suum extract, and displayed reduced inflammatory changes and decreased pro-inflammatory cytokines, indicating that $A$. suum extract was able to reduce hypernociception and synovitis both prophylactically and therapeutically; therefore, this intervention may be effective across a wide clinical spectrum (18). Furthermore, both oral and intraperitoneal administration of A. suum extract has been demonstrated to have a protective role on rats and mice with zymosan-induced arthritis (18). Another study, which assessed the protective anti-inflammatory role of tapeworm (H. diminuta) on RA disease, suggested that this parasite may facilitate significantly less joint inflammation in the CFA animals (33).

The newly identified IL-17-producing pathogenic CD4+ T cell subpopulation Th17 (70), which were defined by their secretion of certain pro-inflammatory cytokines such as IL-17 and TNF- $\alpha$ (71), are major mediators of chronic inflammation and have been implicated in the pathogenesis of various ADs, including RA $(70,72,73)$. The pivotal roles of IL-17 in the pathogenesis of RA has been documented (74). Sufficient volumes of IL-17 were detected in the synovial tissues of RA patients as well as in an experimental model. In a murine CIA model, increased IL-17 levels were detected with aggravated joint inflammation Similarly, alleviated joint pathology was demonstrated to be associated with IL-17 levels and significantly ablated severity was observed in IL-1 $17^{-1}$ mice compared with control groups (73,75). Th17 cells with CCR6 and CCL20 are able to mediate self-destructive immune reactions in joints that may result in autoimmune RA, leading to the hypothesis that intervening in Th17 cell trafficking via CCR6/CCL20 may be a useful method to treat or prevent Th17 cell-mediated ADs such as RA (76).

Th17 cells are known to have a critical role in driving harmful pro-inflammatory responses in AD (77). Th17/IL-17 is IL-23 dependent and TGF- $\beta$ antibody neutralization has been demonstrated to result in decreased levels of IL-17, suggesting that TGF- $\beta$ may also have a critical role in Th17 differentiation (78). Furthermore, production of IL-23 may promote Th17 expression (79). However, treatment with TGF- $\beta$ blockage has not been shown to affect Th17 frequencies and the secretion of IL-17 and IFN- $\gamma$ in CIA models at the initiating phase, suggesting that TGF- $\beta$ is not necessary for Th17 cell differentiation and function (78). Retinoic acid-related orphan nuclear receptor $\gamma \mathrm{t}(\mathrm{ROR} \gamma \mathrm{t})$, which is a pivotal transcription factor of Th17 cells, was downregulated in a CIA mouse infected with various parasites $(18,80,81)$. Supported by various studies, TGF- $\beta$ was undoubtedly expressed in high levels and interpreted as a major cytokine that helps the parasite to successfully suppress Th1 and/or Th17-mediated immune responses which supposedly lead to AD when they are improperly present $(82,83)$. The presence of active TGF- $\beta$ in synovial tissue and synovial fluid in RA patients has been documented in several reports claiming its pivotal pathogenic role in initiating and sustaining chronic inflammation and the destruction of joints (84). TGF- $\beta$ is also positively correlated with disease activity (85). Mice treated with p17, which is a peptide that specifically blocks TGF- $\beta$ signaling, during the initiating phase of CIA resulted in delayed onset and decreased but not significantly reduced severity of RA (86). Another study revealed Th1 cell responses were restricted by Treg cells through a TGF- $\beta$ dependent manner in patients with RA (87). Considering the intense interest in TGF- $\beta$ and the substantial evidence in support of its critical role in parasitic infection immunity, it is safe to speculate that TGF- $\beta$ may have a potential beneficial role during infection with helminthes in $\mathrm{AD}(29)$.

IL-4, which is a Th2 cell-induced cytokine, is able to directly attenuate ongoing Th1-driven autoimmune inflammation $(88,89)$. Administration of IL-4 improved proteoglycan-induced arthritis in mice, and local delivery of IL-4 by retrovirus transuded leukocytes improved experimental CIA $(90,91)$. In addition, an intact adaptive immune response involving $\mathrm{T}$ cells and IL-4R $\alpha$ signaling is required for the anti-arthritic effect of $H$. diminuta infection (33). Following infecting with $S$. mansoni in a CIA mouse, enhanced IL-4 production and reduced IFN- $\gamma$ secretion were detected, which may indicate the skewed response from Th1 to Th2 that is favorable to ameliorate inflammation status (19). Although IFN- $\gamma$ is believed to be a Th1-related cytokine, its role in CIA remains controversial. A report documented that IFN- $\gamma$ receptor-deficient mice exhibited a substantial reduction in the incidence and severity of CIA (92). Furthermore, IFN- $\gamma$ is known to have a significant role in the production of pathogenic antibody anti-type $2 \operatorname{IgG} 2 \alpha(19,92)$. Another study reported the IFN- $\gamma$ receptor knockout mice displayed more accelerated CIA and increased osteoclastogenesis (93).

Together with IL-4, IL-10 is regarded as an important component of the anti-arthritic effect and is known to be an ameliorating factor for CIA in experimental CIA mice (94). As mentioned, parasitic infections are predominantly mediated by Th 2 immune responses. With a wide variety of approaches for immune suppression, parasitic protective effects on autoimmune disorders were generated in the presence of regulatory $\mathrm{T}$ cells and anti-inflammatory cytokines, IL-10 and TGF- $\beta$. As studies have demonstrated, the presence of IL-10 significantly decreases the percentage of Th17 cells $(95,96)$. Under Th17-polarizing conditions, IL-10-deficient and IL-10R-defecient spleen cells produced high levels of IL-17 and ROR $\gamma$ t (96). Some findings demonstrated that IL-10 may be negatively correlated with Th17 cells and its relative cytokines and increased Treg cells in blood and synovial tissue during RA progression both in humans and an experimental murine model $(95,96)$. Reduced RA inflammation and cytokine shiftiness from IFN- $\gamma$ to increased IL-10 and IL-4 production was observed in mice infected with $H$. diminuta, suggesting the anti-arthritic effect of this parasite may be associated with increased IL-10 expression levels (33). In infection with S. mansoni, reduced severity of CIA was also correlated 
with elevated IL-4 and IL-10 production (19). IL-10 knockout mice were not protected by $H$. diminuta infection, and the anti-arthritic effect of this parasite was ablated by the use of IL-10 neutralizing antibodies (33). All the findings of these studies support the hypothesis that IL-10 mat be an attractive therapeutic target in RA, and achieving a balance between Th17 cells and Treg cells by altering IL-10 levels may be a promising treatment for ADs (95).

As a subset of $\mathrm{CD} 4^{+} \mathrm{T}$ cells, Treg cells are known to have a critical role in the prevention and treatment of ADs such as RA, which has been demonstrated by experimental and clinical observation. Treg cells are also considered to be responsible for maintaining self-tolerance in different parasitic infections (97-100). Treg cells have a role in limiting inflammation, regulating adaptive immunity and controlling damage at the inflammatory sites to various pathogens (101). Excretory and/or secretory products from $F$. hepatica have been demonstrated to be promoters of Treg and Th2 cells, and have a suppressive role on the production of pro-inflammatory cytokines and is able to upregulate IL-10 expression. Upon this finding, Carranza et al (102) indicated that the therapeutic effect of this extract was mediated by the activation of dendritic cells (DCs) depending on Treg cells. As the severity of CIA and RA was under the control of Treg cells $(103,104)$, promotion of function and/or an enhanced role of Treg cells resulted in ameliorated experimental and clinical arthritis (105). Schistosome eggs have been shown to activate Treg cells, which may be an important mechanism in the reduction of CIA $(106,107)$.

Antigen-specific immunotherapy is a major therapeutic target for the improvement of autoimmune rheumatic disease. Both the stimulation and modulation of the host immune system by parasites are determined by DC populations. Depletion of DCs ablates the Th2 immune response to infection, whereas isolated DCs pulsed with parasitic antigens readily induce Th2 responsiveness (12). Therefore, DCs are exciting therapeutic targets for autoimmune rheumatic disease (29). The role of DCs in preferentially promoting Th2-cell differentiation during parasitic infection remains unclear, although several studies have indicated that DCs activated by exposure to schistosome egg antigens preferentially support Th2-cell differentiation $(108,109)$. Intravenous injections of DCs have been shown to ameliorate the development and severity of CIA by inducing Foxp3-producing Treg cells and restraining Th17 cell differentiation and function (110). Moreover, DCs have a critical role in maintaining central and peripheral immune tolerance and are responsible for the formation of peripheral Treg cells (111-113). Following treatment with bone marrow CD11b(+) F4/80(+), DCs significantly reduced pathologic scores and cartilage destruction, which was accompanied by decreased Th17 and enhanced Treg cells (110). It has also been demonstrated that excretory and/or secretory products from the $F$. hepatica parasite promoted the differentiation of Th2 and Treg cells (114), plus total extract (TE) is able to modulate the DC maturation by downregulating the pre-inflammatory cytokines (115). Subsequently, Carranza et al (102) demonstrated the pivotal action of TE on DCs to improve the symptoms of CII-induced RA through decreasing pro-inflammatory cytokines, blunted Th1 and Th17 responses and enhancing the TGF- $\beta$-producing Treg cells. Therefore, DCs may contribute to the reduced and suppressive immunopathological responses during RA progression through the promotion of Th2 and Treg cells and blunting the Th17 cells immune responses, further leading to alleviated symptoms.

Another important factor, TNF- $\alpha$, is a cytokine with both pro-inflammatory and immune-regulatory properties. Findings from human and animal studies have indicated the direct involvement of TNF- $\alpha$ in the pathogenesis of arthritis (37), including cartilage destruction and bone resorption, as they can stimulate synovial cells to produce collagenase (17) and inhibit proteoglycan synthesis by articular chondrocytes (35). These findings suggest the pivotal pathogenic role of TNF- $\alpha$ in disease causation. Some biological cytokine blockers targeting TNF- $\alpha$ have already been successfully used in clinical settings (116). As previous studies focusing on the role of parasitic infections on CIA animals have shown, reduced severity of RA is associated with the modulation and regulation of pro-inflammatory cytokines such as TNF- $\alpha$, suggesting a direct involvement of TNF- $\alpha$ in disease pathogenesis. Treatment with anti-TNF- $\alpha$ has been demonstrated to be safe and well-tolerated, resulting in significant clinical and laboratory improvements $(33,82)$. It was shown that the suppressive role of $S$. mansoni on CIA DBA mice was correlated with the reduction of pre-inflammatory cytokines TNF- $\alpha$ (82). Downregulation of TNF- $\alpha$ in S. japonicum infection two weeks prior to CII immunization was also observed and was hypothesized to be related to the reduction of CIA (33). All these findings suggest that TNF- $\alpha$ may be a useful, safe and efficient novel therapeutic target.

\section{Conclusion}

Although a small number of studies have indicated that helminthes infection exaggerated some disease conditions (30-32), numerous human and animal studies that focused on the effect of parasitic infections on RA demonstrated a beneficial role of parasite infection with significant evidence, including reduced incidence and severity and the prevention of further pathogenic progression $(12,16-19,21,33)$. These findings support the 'hygiene hypothesis' theory. Immune modulation during this protective interaction included modulation of $\mathrm{CD}^{+} \mathrm{T}$ cell subsets, inclduing deceased Th1 and Th17 responses, enhanced Treg cell responses, downregulation of pre-inflammatory cytokines (IFN- $\gamma$, IL- 1 and TNF- $\alpha$ ) and upregulation of anti-inflammatory cytokines (IL-4 and IL-10). More advanced research and methods are required to further investigate the exact mechanisms and potential beneficial role of parasites on RA.

\section{Acknowledgements}

This work was supported by grants from the Youth Natural Science Foundation of Xinjiang (grant no. 2014211C081).

\section{References}

1. Davidson A and Diamond B: Autoimmune diseases. N Engl J Med 345: 340-350, 2001.

2. Hollan I, Meroni PL, Ahearn JM, Cohen Tervaert JW, Curran S, Goodyear CS, Hestad KA, Kahaleh B, Riggio M, Shields K and Wasko MC: Cardiovascular disease in autoimmune rheumatic diseases. Autoimmun Rev 12: 1004-115, 2013. 
3. Cooper GS, Bynum ML and Somers EC: Recent insights in the epidemiology of autoimmune diseases: Improved prevalence estimates and understanding of clustering of diseases. J Autoimmun 33: 197-207, 2009.

4. Hayter SM and Cook MC: Updated assessment of the prevalence, spectrum and case definition of autoimmune disease. Autoimmun Rev 11: 754-765, 2012.

5. Wahren-Herlenius $M$ and Dörner T: Immunopathogenic mechanisms of systemic autoimmune disease. Lancet 382 819-831, 2013

6. Somers EC, Thomas SL, Smeeth L and Hall AJ: Autoimmune diseases co-occurring within individuals and within families: A systematic review. Epidemiology 17: 202-217, 2006.

7. Fina-Aviles F, Medina-Peralta M,Mendez-Boo L,HermosillaE, Elorza JM, Garcia-Gil M, Ramos R, Bolibar B, Javaid MK, Edwards CJ, et al: The descriptive epidemiology of rheumatoid arthritis in Catalonia: A retrospective study using routinely collected data. Clin Rheumatol 35: 751-757, 2016.

8. Cotsapas C, Voight BF, Rossin E, Lage K, Neale BM, Wallace C, Abecasis GR, Barrett JC, Behrens T, Cho J, et al: Pervasive sharing of genetic effects in autoimmune disease. PLoS Genet 7: e1002254, 2011.

9. Maruotti N, d'Onofrio F and Cantatore FP: Metabolic syndrome and chronic arthritis: Effects of anti-TNF- $\alpha$ therapy. Clin Exp Med 27: 433-438, 2015

10. Bilecik NA, Tuna S, Samanci N, Balci N and Akbas H: Prevalence of metabolic syndrome in women with rheumatoid arthritis and effective factors. Int J Clin Exp Med 7: 2258-2256, 2014.

11. Zhang J, Fu L, Shi J, Chen X, Li Y, Ma B and Zhang Y: The risk of metabolic syndrome in patients with rheumatoid arthritis: A meta-analysis of observational studies. PLoS One 8: e78151, 2013.

12. Johnston MJ, MacDonald JA and McKay DM: Parasitic helminths: A pharmacopeia of anti-inflammatory molecules. Parasitology 136: 125-147, 2009.

13. Richard-Miceli $C$ and Criswell LA: Emerging patterns of genetic overlap across autoimmune disorders. Genome Med 4: 6, 2012.

14. Im CH, Kim NR, Kang JW, Kim JH, Kang JY, Bae GB Nam EJ and Kang YM: Inflammatory burden interacts with conventional cardiovascular risk factors for carotid plaque formation in rheumatoid arthritis. Rheumatology (Oxford) 9: $808-815,2015$

15. Rubbert-Roth A: Assessing the safety of biologic agents in patients with rheumatoid arthritis. Rheumatology (Oxford) 51 (Suppl 5): v38-v47, 2012.

16. Greenwood BM, Voller A and Herrick EM: Suppression of adjuvant arthritis by infection with a strain of the rodent malaria parasite Plasmodium berghei. Ann Rheum Dis 29 321-333, 1970

17. Pearson DJ and Taylor G: The influence of the nematode Syphacia oblevata on adjuvant arthritis in the rat. Immunology 29: 391-396, 1975

18. Rocha FA, Leite AK, Pompeu MM, Cunha TM, Verri WA Jr, Soares FM, Castro RR and Cunha FQ: Protective effect of an extract from Ascaris suum in experimental arthritis models. Infect Immun 76: 2736-2745, 2008.

19. Osada Y, Shimizu S, Kumagai T, Yamada S and Kanazawa T: Schistosoma mansoni infection reduces severity of collagen-induced arthritis via down-regulation of pro-inflammatory mediators. Int J Parasitol 39: 457-464, 2009.

20. Zaccone P, Fehervari Z, Phillips JM, Dunne DW and Cooke A: Parasitic worms and inflammatory diseases. Parasite Immunol 28: 515-523, 2006

21. Greenwood BM, Herrick EM and Voller A: Can parasitic infection suppress autoimmune disease? Proc R Soc Med 63 : $19-20,1970$.

22. Espinoza-Jiménez A, Rivera-Montoya I, Cárdenas-Arreola R Morán Land Terrazas LI: Taenia crassiceps infection attenuates multiple low-dose streptozotocin-induced diabetes. J Biomed Biotechnol 2010: 850541, 2010.

23. Taylor G and Walker J: CharlesHarrison, Blackley 1820-1900. Clin Allergy 3: 103-108, 1973.

24. Strachan DP: Hay fever, hygiene, and household size. BMJ 299: 1259-1260, 1989.

25. Rook GA: 99th Dahlem conference on infection, inflammation and chronic inflammatory disorders: Darwinian medicine and the 'hygiene' or 'old friends' hypothesis. Clin Exp Immunol 160: 70-79, 2010.
26. Reyes JL, Espinoza-Jiménez AF, González MI, Verdin L and Terrazas LI: Taenia crassiceps infection abrogates experimental autoimmune encephalomyelitis. Cell Immunol 267: 77-87, 2011.

27. La Flamme AC, Ruddenklau K and Bäckström BT: Schistosomiasis decreases central nervous system inflammation and alters the progression of experimental autoimmune encephalomyelitis. Infect Immun 71: 4996-5004, 2003.

28. Somers EC, Thomas SL, Smeeth L and Hall AJ: Autoimmune diseases co-occurring within individuals and within families: A systematic review. Epidemiology 17: 202-227, 2006.

29. McKay DM: The beneficial helminth parasite? Parasitology 132 $1-12,2006$

30. Graepel R, Leung G, Wang A, Villemaire M, Jirik FR, Sharkey KA, McDougall JJ and McKay DM: Murine autoimmune arthritis is exaggerated by infection with the rat tapeworm, Hymenolepis diminuta. Int J Parasitol 43: 593-601, 2013.

31. Hunter MM, Wang A and McKay DM: Helminth infection enhances disease in a murine TH2 model of colitis. Gastroenterology 132: 1320-1330, 2007.

32. Chen CC, Louie S, McCormick B, Walker WA and Shi HN: Concurrent infection with an intestinal helminth parasite impairs host resistance to enteric Citrobacter rodentium and enhances Citrobacter-induced colitis in mice. Infect Immun 73 $5468-5481,2005$

33. Shi M, Wang A, Prescott D, Waterhouse CC, Zhang S, McDougall JJ, Sharkey KA and McKay DM: Infection with an intestinal helminth parasite reduces Freund's complete adjuvant-induced monoarthritis in mice. Arthritis Rheum 63 : 434-444, 2011

34. Balic A, Harcus Y, Holland MJ and Maizels RM: Selective maturation of dendritic cells by Nippostrongylus brasiliensis-secreted proteins drives Th2 immune responses. Eur J Immunol 34: 3047-3059, 2004.

35. Smits HH, Everts B, Hartgers FC and Yazdanbakhsh M: Chronic helminth infections protect against allergic diseases by active regulatory processes. Curr Allergy Asthma Rep 10: 3-12, 2010.

36. Harn DA, McDonald J, Atochina O and Da'dara AA: Modulation of host immune responses by helminth glycans. Immunol Rev 230: 247-257, 2009.

37. Daniłowicz-Luebert E, O'Regan NL, Steinfelder S and Hartmann S: Modulation of specific and allergy-related immune responses by helminths. J Biomed Biotechnol 2011: 821578, 2011

38. Bouchery T, Kyle R, Ronchese F and Le Gros G: The differentiation of CD4 (+) T-helper cell subsets in the context of helminth parasite infection. Front Immunol 5: 487, 2014.

39. Vignali DA, Crocker P, Bickle QD, Cobbold S, Waldmann H and Taylor MG: A role for CD4+ but not CD8+ T cells in immunity to Schistosoma mansoni induced by 20 krad-irradiated and Ro 11-3128-terminated infections. Immunology 67: 466-472, 1989.

40. Katona IM, Urban JF Jr and Finkelman FD: The role of L3T4+ and Lyt-2+ T cells in the IgE response and immunity to Nippostrongylus brasiliensis. J Immunol 140: 3206-3211, 1988.

41. UrbanJF Jr, Noben-Trauth N, Donaldson DD, Madden KB, Morris SC, Collins M and Finkelman FD: IL-13, IL-4Ralpha and Stat6 are required for the expulsion of the gastrointestinal nematode parasite Nippostrongylus brasiliensis. Immunity 8: 255-264, 1998

42. Allen JE and Maizels RM: Diversity and dialogue in immunity to helminths. Nat Rev Immunol 11: 375-358, 2011.

43. Zhu J, Min B, Hu-Li J, Watson CJ, Grinberg A, Wang Q, Killeen N, Urban JF Jr, Guo L and Paul WE: Conditional deletion of Gata3 shows its essential function in T $(\mathrm{H}) 1-\mathrm{T}(\mathrm{H}) 2$ responses. Nat Immunol 5: 1157-1165, 2004.

44. Zhang Y, Chen L, Gao W, Hou X, Gu Y, Gui L, Huang D, Liu M, Ren C, Wang S and Shen J: IL-17 neutralization significantly ameliorates hepatic granulomatous inflammation and liver damage in Schistosoma japonicum infected mice. Eur J Immunol 42: 1523-1535, 2012.

45. Rutitzky LI, Lopes da Rosa JR and Stadecker MJ: Severe CD4 T cell-mediated immunopathology in murine schistosomiasis is dependent on IL-12p40 and correlates with high levels of IL-17. J Immunol 175: 3920-3926, 2005.

46. Baumgart M, Tompkins F, Leng J and Hesse M: Naturally occurring CD4+Foxp3+ regulatory $\mathrm{T}$ cells are an essential, IL-10-independent part of the immunoregulatory network in Schistosoma mansoni egg-induced inflammation. J Immunol 176: 5374-5387, 2006 
47. Taylor MD, LeGoff L, Harris A, Malone E, Allen JE and Maizels RM: Removal of regulatory $\mathrm{T}$ cell activity reverses hyporesponsiveness and leads to filarial parasite clearance in vivo. J Immunol 174: 4924-4933, 2005.

48. Taylor JJ, Mohrs M and Pearce EJ: Regulatory T cell responses develop in parallel to Th responses and control the magnitude and phenotype of the Th effector population. J Immunol 176: $5839-5847,2006$

49. Faulkner H, Humphreys N, Renauld JC, Van Snick J and Grencis R: Interleukin-9 is involved in host protective immunity to intestinal nematode infection. Eur J Immunol 27: 2536-2540, 1997.

50. Harris ED Jr: Rheumatoid arthritis. Pathophysiology and implications for therapy. N Engl J Med 322: 1277-2289, 1990.

51. Schulze-Koops $H$ and Kalden JR: The balance of Th1/Th2 cytokines in rheumatoid arthritis. Best Pract Res Clin Rheumatol 15: 677-691, 2001.

52. Choy EH and Panayi GS: Cytokine pathways and joint inflammation in rheumatoid arthritis. N Engl J Med 344: 907-916, 2001.

53. Kong YY, Feige U, Sarosi I, Bolon B, Tafuri A, Morony S, Capparelli C, Li J, Elliott R, McCabe S, et al: Activated T cells regulate bone loss and joint destruction in adjuvant arthritis through osteoprotegerin ligand. Nature 402: 304-309, 1999.

54. Mitamura M, Nakano N, Yonekawa T, Shan L, Kaise T, Kobayashi T, Yamashita K, Kikkawa H and Kinoshita M: $\mathrm{T}$ cells are involved in the development of arthritis induced by anti-type II collagen antibody. Int Immunopharmacol 7: 1360-1368, 2007

55. Billingham ME: Models of arthritis and the search for anti-arthritic drugs. Pharmacol Ther 21: 389-428, 1983.

56. Cho YG, Cho ML, Min SY and Kim HY: Type II collagen autoimmunity in a mouse model of human rheumatoid arthritis. Autoimmun Rev 7: 65-70, 2007.

57. Balkwill FR and Burke F: The cytokine network. Immunol Today 10: 299-304, 1989.

58. Shingu M, Nagai $Y$, Isayama $T$, Naono T, Nobunaga $M$ and Nagai Y: The effects of cytokines on metalloproteinase inhibitors (TIMP) and collagenase production by human chondrocytes and TIMP production by synovial cells and endothelial cells. Clin Exp Immunol 94: 145-149, 1993.

59. Vermeire K, Heremans H, Vandeputte M, Huang S, Billiau A and Matthys P: Accelerated collagen-induced arthritis in IFN-gamma receptor-deficient mice. J Immunol 158: 5507-5513, 1997.

60. Kelchtermans H,Billiau A and Matthys P: How interferon-gamma keeps autoimmune diseases in check. Trends Immunol 29: 479-486, 2008

61. Guedez YB, Whittington KB, Clayton JL, Joosten LA, van de Loo FA, van den Berg WB and Rosloniec EF: Genetic ablation of interferon-gamma up-regulates interleukin-1beta expression and enables the elicitation of collagen-induced arthritis in a nonsusceptible mouse strain. Arthritis Rheum 44: 2413-2424, 2001.

62. Manoury-Schwartz B, Chiocchia G, Bessis N, Abehsira-Amar O, Batteux F, Muller S, Huang S, Boissier MC and Fournier C: High susceptibility to collagen-induced arthritis in mice lacking IFN-gamma receptors. J Immunol 158: 5501-5506, 1997.

63. Remmers EF, Plenge RM, Lee AT, Graham RR, Hom G Behrens TW, de Bakker PI, Le JM, Lee HS, Batliwalla F, et al: STAT4 and the risk of rheumatoid arthritis and systemic lupus erythematosus. N Engl J Med 357: 977-986, 2007.

64. Trinchieri G: Interleukin-12 and the regulation of innate resistance and adaptive immunity. Nat Rev Immunol 3: 133-146, 2003.

65. Boissier MC: Cell and cytokine imbalances in rheumatoid synovitis. Joint Bone Spine 78: 230-234, 2011.

66. Chen R, Tao Y, Qiu K, Huang W, Huang C and Li J: Association of circulating Treg cells with disease activity in patients with rheumatoid arthritis. Nan Fang Yi Ke Da Xue Xue Bao 32: 886-889, 2012 (In Chinese)

67. Groux H, O'Garra A, Bigler M, Rouleau M, Antonenko S, de Vries JE and Roncarolo MG: A CD4+ T-cell subset inhibits antigen-specific T-cell responses and prevents colitis. Nature 389: 737-742, 1997

68. O'Garra A and Vieira P: Regulatory T cells and mechanisms of immune system control. Nat Med 10: 801-805, 2004.

69. Schopf LR, Hoffmann KF, Cheever AW, Urban JF Jr and Wynn TA: IL-10 is critical for host resistance and survival during gastrointestinal helminth infection. J Immunol 168: 2383-2392, 2002 .
70. Harrington LE, Hatton RD, Mangan PR, Turner H, Murphy TL, Murphy KM and Weaver CT: Interleukin 17-producing CD4+ effector T cells develop via a lineage distinct from the Thelper type 1 and 2 lineages. Nat Immunol 6: 1123-1132, 2005.

71. Langrish CL Chen Y, Blumenschein WM, Mattson J, Basham B, Sedgwick JD, McClanahan T, Kastelein RA and Cua DJ: IL-23 drives a pathogenic T cell population that induces autoimmune inflammation. J Exp Med 201: 233-240, 2005.

72. Hirota K, Hashimoto M, Yoshitomi H, Tanaka S, Nomura T, Yamaguchi T, Iwakura Y, Sakaguchi N and Sakaguchi S: $\mathrm{T}$ cell self-reactivity forms a cytokine milieu for spontaneous development of IL-17+ Th cells that cause autoimmune arthritis. J Exp Med 204: 41-47, 2007.

73. Nakae S, Nambu A, Sudo K and Iwakura Y: Suppression of immune induction of collagen-induced arthritis in IL-17-deficient mice. J Immunol 171: 6173-6177, 2003.

74. Lubberts E, van den Bersselaar L, Oppers-Walgreen B Schwarzenberger P, Coenen-de Roo CJ, Kolls JK, Joosten LA and van den Berg WB: IL-17 promotes bone erosion in murine collagen-induced arthritis through loss of the receptor activator of NF-kappaB ligand/osteoprotegerin balance. J Immunol 170: 2655-2662, 2003

75. van den Berg WB and Miossec P: IL-17 as a future therapeutic target for rheumatoid arthritis. Nat Rev Rheumatol 5: 549-553, 2009

76. Hirota K, Yoshitomi H, Hashimoto M, Maeda S, Teradaira S, Sugimoto N, Yamaguchi T, Nomura T, Ito H, Nakamura T, et al: Preferential recruitment of CCR6-expressing Th17 cells to inflamed joints via CCL20 in rheumatoid arthritis and its animal model. J Exp Med 204: 2803-2812, 2007.

77. Cua DJ, Sherlock J, Chen Y, Murphy CA, Joyce B, Seymour B, Lucian L, To W, Kwan S, Churakova T, et al: Interleukin-23 rather than interleukin-12 is the critical cytokine for autoimmune inflammation of the brain. Nature 421: 744-748, 2003.

78. Tallima H, Salah M, Guirguis FR and E Ridi R: Transforming growth factor-beta and Th17 responses in resistance to primary murine Schistosomiasis mansoni. Cytokine 48: 239-245, 2009.

79. Chen Z and O'Shea JJ: Regulation of IL-17 production in human lymphocytes. Cytokine 41: 71-78, 2008.

80. Azizi G, Jadidi-Niaragh F and Mirshafiey A: Th17 cells in immunopathogenesis and treatment of rheumatoid arthritis. Int J Rheum Dis 16: 243-253, 2013

81. Roeleveld DM and Koenders MI: The role of the Th17 cytokines IL-17 and IL-22 in Rheumatoid Arthritis pathogenesis and developments in cytokine immunotherapy. Cytokine 74 : 101-107, 2015.

82. Song X, Shen J, Wen H, Zhong Z, Luo Q, Chu D, Qi Y, Xu Y and Wei W: Impact of Schistosoma japonicum infection on collagen-induced arthritis in DBA/1 mice: A murine model of human rheumatoid arthritis. PLoS One 6: e23453, 2011.

83. Mattsson L, Larsson P, Erlandsson-Harris H, Klareskog L and Harris RA: Parasite-mediated down-regulation of collagen-induced arthritis (CIA) in DA rats. Clin Exp Immunol 122: 477-483, 2000.

84. Brennan FM, Chantry D, Turner M, Foxwell B, Maini R and Feldmann M: Detection of transforming growth factor-beta in rheumatoid arthritis synovial tissue: Lack of effect on spontaneous cytokine production in joint cell cultures. Clin Exp Immunol 81: 278-285, 1990

85. Pohlers D, Beyer A, Koczan D, Wilhelm T, Thiesen HJ and Kinne RW: Constitutive upregulation of the transforming growth factor-beta pathway in rheumatoid arthritis synovial fibroblasts. Arthritis Res Ther 9: R59, 2007.

86. Gonzalo-Gil E, do G, Santiago B, Dotor J, Pablos JL and Galindo M: Transforming growth factor (TGF) $\beta$ signalling is increased in rheumatoid synovium but TGF- $\beta$ blockade does not modify experimental arthritis. Clin Exp Immunol 174: 245-255, 2013.

87. McGovern JL, Nguyen DX, Notley CA, Mauri C, Isenberg DA and Ehrenstein MR: Th17 cells are restrained by Treg cells via the inhibition of interleukin-6 in patients with rheumatoid arthritis responding to anti-tumor necrosis factor antibody therapy. Arthritis Rheum 64: 3129-3138, 2012.

88. Oh SJ and DH Chung DH: Invariant NKT cells producing IL-4 or IL-10, but not IFN-gamma, inhibit the Th1 response in experimental autoimmune encephalomyelitis, whereas none of these cells inhibits the Th17 response. J Immunol 186: 6815-6821, 2011 
89. Song GG, Bae SC, Kim JH and Lee YH: Interleukin-4, interleukin-4 receptor, and interleukin-18 polymorphisms and rheumatoid arthritis: A meta-analysis. Immunol Invest 42: $455-469,2013$

90. Finnegan A, Grusby MJ, Kaplan CD, O'Neill SK, Eibel H Koreny T, Czipri M, Mikecz K and Zhang J: IL-4 and IL-12 regulate proteoglycan-induced arthritis through Stat-dependent mechanisms. J Immunol 169: 3345-3352, 2002.

91. Cao Y, Brombacher F, Tunyogi-Csapo M, Glant TT and Finnegan A: Interleukin-4 regulates proteoglycan-induced arthritis by specifically suppressing the innate immune response. Arthritis Rheum 56: 861-870, 2007.

92. Kageyama Y,Koide Y,Yoshida A,Uchijima M,Arai T,Miyamoto S, Ozeki T, Hiyoshi M, Kushida K and Inoue T: Reduced susceptibility to collagen-induced arthritis in mice deficient in IFN-gamma receptor. J Immunol 161: 1542-1548, 1998.

93. De Klerck B, Carpentier I, Lories RJ, Habraken Y, Piette J, Carmeliet G, Beyaert R, Billiau A and Matthys P: Enhanced osteoclast development in collagen-induced arthritis in interferon-gamma receptor knock-out mice as related to increased splenic CD11b+ myelopoiesis. Arthritis Res Ther 6: R220-R231, 2004.

94. Joosten LA, Lubberts E, Helsen MM, Saxne T, Coenen-de Roo CJ, Heinegård D and van den Berg WB: Protection against cartilage and bone destruction by systemic interleukin- 4 treatment in established murine type II collagen-induced arthritis. Arthritis Res 1: 81-91, 1999.

95. Heo YJ, Joo YB, Oh HJ, Park MK, Heo YM, Cho ML, Kwok SK, Ju JH, Park KS, Cho SG, et al: IL-10 suppresses Th17 cells and promotes regulatory $\mathrm{T}$ cells in the CD4+ T cell population of rheumatoid arthritis patients. Immunol Lett 127: 150-156, 2010.

96. Gu Y, Yang J, Ouyang X, Liu W, Li H, Yang J, Bromberg J, Chen SH, Mayer L, Unkeless JC and Xiong H: Interleukin 10 suppresses Th17 cytokines secreted by macrophages and T cells. Eur J Immunol 38: 1807-1813, 2008.

97. Wang J, Lin R, Zhang W, Li L, Gottstein B, Blagosklonov O, Lü G, Zhang C, Lu X, Vuitton DA and Wen H: Transcriptional profiles of cytokine/chemokine factors of immune cell-homing to the parasitic lesions: A comprehensive one-year course study in the liver of E. PLoS One 9: e91638, 2014

98. Anthony RM, Rutitzky LI, Urban JF Jr, Stadecker MJ and Gause WC: Protective immune mechanisms in helminth infection. Nat Rev Immunol 7: 975-987, 2007.

99. Layland LE, Mages J, Loddenkemper C, Hoerauf A, Wagner H, Lang R and da Costa CU: Pronounced phenotype in activated regulatory T cells during a chronic helminth infection. J Immunol 184: 713-724, 2010.

100. Tuxun T, Wang JH, Lin RY, Shan JY, Tai OW, Li T, Zhang JH, Zhao JM and Wen H: Th17/Treg imbalance in patients with liver cystic echinococcosis. Parasite Immunol 34: 520-527, 2012.

101. Lee DM and Weinblatt ME: Rheumatoid arthritis. Lancet 358 903-911, 2001.

102. Carranza F, Falcón CR, Nuñez N, Knubel C, Correa SG, Bianco I, Maccioni M, Fretes R, Triquell MF, Motrán CC and Cervi L: Helminth antigens enable CpG-activated dendritic cells to inhibit the symptoms of collagen-induced arthritis through Foxp3+ regulatory T cells. PLoS One 7: e40356, 2012.

103. van Amelsfort JM, van Roon JA, Noordegraaf M, Jacobs KM, Bijlsma JW, Lafeber FP and Taams LS: Proinflammatory mediator-induced reversal of $\mathrm{CD} 4+, \mathrm{CD} 25+$ regulatory $\mathrm{T}$ cell-mediated suppression in rheumatoid arthritis. Arthritis Rheum 56: 732-742, 2007.
104. Morgan ME, Flierman R, van Duivenvoorde LM, Witteveen HJ, van Ewijk W, van Laar JM, de Vries RR and Toes RE: Effective treatment of collagen-induced arthritis by adoptive transfer of CD25+ regulatory T cells. Arthritis Rheum 52: 2212-2221, 2005.

105. Esensten JH, Wofsy D and Bluestone JA: Regulatory T cells as therapeutic targets in rheumatoid arthritis. Nat Rev Rheumatol 5: 560-565, 2009.

106. Yang J, Zhao J, Yang Y, Zhang L, Yang X, Zhu X, Ji M, Sun N and Su C: Schistosoma japonicum egg antigens stimulate CD4 CD25 T cells and modulate airway inflammation in a murine model of asthma. Immunology 120: 8-18, 2007.

107. Mo HM, Liu WQ, Lei JH, Cheng YL, Wang CZ and Li YL: Schistosoma japonicum eggs modulate the activity of CD4+ CD25+ Tregs and prevent development of colitis in mice. Exp Parasitol 116: 385-389, 2007.

108. Jankovic D,Kullberg MC,CasparP and Sher A:Parasite-induced Th2 polarization is associated with down-regulated dendritic cell responsiveness to Th1 stimuli and a transient delay in T lymphocyte cycling. J Immunol 173: 2419-2427, 2004

109. Cervi L, MacDonald AS, Kane C, Dzierszinski F and Pearce EJ: Cutting edge: Dendritic cells copulsed with microbial and helminth antigens undergo modified maturation, segregate the antigens to distinct intracellular compartments and concurrently induce microbe-specific Th1 and helminth-specific Th2 responses. J Immunol 172: 2016-1020, 2004.

110. Zhang L, Fu J, Sheng K, Li Y, Song S, Li P, Song S, Wang Q, Chen J, Yu J and Wei W: Bone marrow CD11b (+)F4/80 (+) dendritic cells ameliorate collagen-induced arthritis through modulating the balance between Treg and Th17. Int Immunopharmacol 25: 96-105, 2015.

111. Saei A and Hadjati J: Tolerogenic dendritic cells: Key regulators of peripheral tolerance in health and disease. Int Arch Allergy Immunol 161: 293-303, 2013.

112. Stoop JN, Harry RA, von Delwig A, Isaacs JD, Robinson JH and Hilkens CM: Therapeutic effect of tolerogenic dendritic cells in established collagen-induced arthritis is associated with a reduction in Th17 responses. Arthritis Rheum 62: 3656-3665, 2010

113. Torres-Aguilar H, Aguilar-Ruiz SR, González-Pérez G Munguía R, Bajaña S, Meraz-Ríos MA and Sánchez-Torres C: Tolerogenic dendritic cells generated with different immunosuppressive cytokines induce antigen-specific anergy and regulatory properties in memory CD4+ T cells. J Immunol 184: 1765-1775, 2010.

114. Falcón C, Carranza F, Martínez FF, Knubel CP, Masih DT, Motrán CC and Cervi L: Excretory-secretory products (ESP) from Fasciola hepatica induce tolerogenic properties in myeloid dendritic cells. Vet Immunol Immunopathol 137: 36-46, 2010.

115. Falcón CR, Carranza FA, Aoki P, Motrán CC and Cervi L: Adoptive transfer of dendritic cells pulsed with Fasciola hepatica antigens and lipopolysaccharides confers protection against fasciolosis in mice. J Infect Dis 205: 506-514, 2012.

116. Harnett W and Harnett MM: Helminth-derived immunomodulators: Can understanding the worm produce the pill? Nat Rev Immunol 10: 278-284, 2010. 